\title{
Penggunaan Media dalam Pengekalan Identiti Etnik Generasi Kedua Bawean di Malaysia
}

\author{
MUHAMAMD RIDHWAN SARIFIN \\ Universiti Pendidikan Sultan Idris \\ MOHAMAD FAUZI SUKIMI \\ MOHD NOR SHAHIZAN ALI \\ Universiti Kebangsaan Malaysia
}

\begin{abstract}
ABSTRAK
Identiti merupakan satu perkara yang penting bagi manusia dan sering dibincangkan. Kepentingan identiti ini adalah berkaitan dengan proses-proses identiti iaitu pembentukan, pengekalan dan perubahan. Perdebatan proses ini merangkumi aspek etnik, bahasa, agama, gender, makanan, persekitaran dan lokalisme. Pada masa kini, pengekalan identiti sangat dipengaruhi melalui penggunanaan platform media. Artikel ini bertujuan mengupas platform media yang digunakan oleh generasi kedua Bawean dan membincangkan kesan media ke atas pengekalan identiti. Kajian ini menggunakan pendekatan kualitatif melalui kaedah temu bual mendalam terhadap 13 orang informan dan kajian perpustakaan. Temu bual dianalisis berdasarkan teori pembentukan identiti budaya. Hasil kajian dari temu bual mendapati platform media yang digunakan oleh generasi kedua adalah media elektronik meliputi media sosial dan media penyiaran seperti radio dan televisyen. Media elektronik digunakan sebagai strategi pengekalan identiti. Media cetak seperti majalah merupakan sebahagian koleksi yang disimpan untuk pembelajaran mengenai identiti. Kesan penggunaan media mempengaruhi pembentukan budaya identiti generasi kedua Bawean ke atas ciri fizikal, personaliti, kemahiran, proses psikologikal, hak dan tanggungjawab mereka. Platform media ini secara langsung memberi peneguhan dan pengekalan identiti etnik mereka. Pengekalan identiti etnik masyarakat Bawean dilestarikan apabila setiap generasi mempunyai kesedaran dan tanggungjawab untuk menonjolkan identiti etnik mereka melalui penggunaan media.
\end{abstract}

Kata kunci: Platform media, identiti etnik, generasi kedua, orang Bawean, Malaysia.

\section{Media Using on the Maintenance Ethnic Identity of the Second Generation of the Bawean in Malaysia}

\begin{abstract}
The formation of identity is derived from biology and the social environment. The biology of genetics is still ongoing. Whereas the social environment is affected by the surrounding environment. In modern times, identity formation remained largely influenced by media platforms. This article is intended to uncover the media platform used by the second generation of Bawean people. Second, this article discusses the media's impact on the retention of their identities, especially the second generation of Bawean people. This study is based on a qualitative approach through in-depth interviews with specialised informants and library studies. Interviews were analysed on the basis of questions of identity formation derived from the model of Hong et al. (2001). The study found that the platform media used by the second generation are electronic media, including social media and broadcast media, such as radio and television. Print media is part of a collection that is kept for learning. The impact of media uses affects responses to physical characteristics, personality, skills,
\end{abstract}


psychological processes and rights and responsibilities. This media platform directly affirms and retains their ethnic identity. Maintaining ethnic identity Bawean can be preserved as each generation has the awareness and responsibility to promote their ethnic identity through media.

Keywords: Platform media, ethnic identity, second generation, Bawean people, Malaysia.

\section{PENGENALAN}

Media sebagai salah satu medium komunikasi bukan sahaja telah memberikan manfaat kepada masyarakat atas penyebaran maklumat tetapi juga telah membentuk tingkah laku secara peribadi. Jenis media yang pelbagai memberikan masyarakat sentiasa berlumbalumba untuk mengemaskini segala bentuk personaliti yang akhirnya boleh dikenali sebagai sesebuah kumpulan mahupun etnik. Sebelum adanya media, penyebaran maklumat tentang sesebuah identiti personaliti individu, kumpulan mahupun etnik tidak diketahui sehingga wujudnya media seperti gambar, lukisan dan video (Eddy, 2013). Ahli antropologi dan arkeologi telah mula menyebarkan maklumat kehidupan identiti masyarakat melalui lukisan sesuatu masyarakat yang terdapat di dinding-dinding gua dan bangunan yang boleh dikenali sebagai antropologi visual atau dokumentari. Lukisan-lukisan tersebut dibukukan untuk memperlihatkan bahawa media telah menyebarkan maklumat kehidupan masyarakat di masa lampau sebagai bukti untuk menguatkan fakta (Marcus \& Ruby, 2011).

Pada masa kini, penyebaran maklumat tentang kehidupan individu mahupun masyarakat umumnya menggunakan media alternatif iaitu media sosial. Mengambil contoh tentang penyebaran maklumat identiti sesuatu etnik, media tradisional seperti buku, helaian dan majalah merupakan bahan atau sumber ilmu yang berkekalan serta sukar ditemui. Media merupakan agen penting sosialisasi dan juga pengantara realiti politik serta perlu dilihat sebagai institusi utama masyarakat kontemporari dengan pelbagai pengaruh ekonomi, politik, budaya dan kesan sosial. Malah, media merupakan satu sistem pengeluaran kebudayaan yang dikuasai melalui filem, radio, penyiaran, akhbar, dan majalah telah mewujudkan subsistensi ke sistem pengguna kapitalisme seperti mana dinyatakan dalam kamus sosiologi (Turner, 2006). Oleh demikian, pengguna sentiasa terdedah dengan maklumat atau perkara-perkara yang mendorong tingkah laku seseorang.

Peranan media sangat mempengaruhi kehidupan. Mobasher (2006) menjelaskan bahawa stigma mahupun stereotaip yang berlegar di media menyebabkan masyarakat Iran menyembunyikan identiti asal mereka di Amerika. Mereka lebih mahu dikenali sebagai orang Amerika yang terkandung dalam konsep negara-bangsa. Gündüz (2017) menjelaskan platform media mempunyai kepentingan yang kuat dalam kehidupan kerana ia adalah tempat di mana kita "mempamerkan" pengalaman hidup kita. Platform ini juga mencerminkan pelbagai dimensi mengenai kedudukan kita dalam kehidupan sosial maya dan fizikal. Kedua-dua faktor ini telah membuat orang ramai memainkan watak tertentu di arena sosial. Tambah Gündüz, media sosial menyerlahkan ekspresi, eksplorasi dan percubaan identiti sesuatu yang semulajadi untuk pengalaman manusia. Maslida (2018) pula menjelaskan bahawa media telah mengubah lanskap komunikasi dengan memberi ruang yang luas kepada identiti untuk berkembang khususnya dalam pengunaan bahasa untuk lebih dikenali terhadap ciri identiti mahupun etnik mereka.

la merupakan agensi dalam kehidupan nyata yang menyediakan komuniti internet dan interaksi yang mereka buat dalam diri mereka. Adalah penting untuk memahami motif agensi untuk memahami tentang interaksi kumpulan pada platform sosial. Interaksi tersebut membolehkan individu hadir kepada orang lain dan menentukan cara mereka ingin melihat 
sebagai tambahan untuk membantu mereka berhubung dan berinteraksi dengan orang dan mengambil bahagian dalam aktiviti yang mereka kehendaki. la lebih jelas apabila seseorang mempunyai tujuan yang sama dalam interaksi (Gündüz, 2017). Ini kerana maklumat menjadi mudah dipindahkan kepada komuniti yang luas. Pada masa ini, orang boleh mengakses maklumat yang diperlukan tanpa penangguhan seperti mana kaedah media tradisional. Teknologi komunikasi baharu ruang siber khususnya, telah menjadi medium penting untuk penciptaan, perundingan, dan prestasi identiti (Saucier, 2009).

Dalam persekitaran maya, seseorang individu dimasukkan ke dalam lingkungan yang sama apabila mereka mahu. Individu tersebut membuat profil yang mewakili diri mereka dan berinteraksi dengan orang lain secara lansung atau dalam bentuk bertulis. Pembentukan identiti dalam zaman digital dijelaskan oleh Manago (2015) dengan melibatkan diri kepada ruang dalam talian melalui skrin yang sama dan media yang diakses secara komersial. Dalam pembentukan identiti di media sosial khususnya, apa yang dipertaruhkan adalah rasa keaslian dan nilai diri yang melampaui nilai komersial. Ini akan mewujudkan satu pendekatan rasa sepunya terhadap lingkungan.

Jenis maklumat yang diterima dari media mempunyai implikasi untuk bagaimana kita melihat budaya kita sendiri serta budaya lain. Clément et al. (2005) berpendapat bahawa pengantara komunikasi menjadi bentuk komunikasi yang paling penting antara budaya. Mereka dapat mempunyai rasa kesepunyaan apabila sesuatu identiti budaya yang mereka amalkan disembahkan di dalam media sosial. Menurut Halime Yücel (2019), identiti kebudayaan pada mulanya dan terpenting adalah "shared individuality" di mana pelaku sosial membangun, mengaktifkan dan mengubahsuai dalam konteks interaksi sosial dan sejarah mengikut isu-isu tertentu yang menyebabkan mereka bertindak. Media muncul sebagai cermin budaya memberikan nilai simbolik jenama dan identiti naratif kepada penerima mesej. Media membantu dalam budaya sehari-hari bertujuan mewakili pengalaman dan keprihatinan bersama sesebuah komuniti. Aspek ini bertujuan untuk menyatukan imej yang bersatu dan tidak berubah (yang menunjukkan dirinya dalam wacana perkongsian karekter etnik.

Halime Yücel (2019) menghuraikan bahawa media cenderung menjadi tempat yang istimewa untuk membenarkan nilai dalam lapangan sosial. Oleh itu, ia melampaui batas ruang komersial dengan mempengaruhi secara tidak langsung dan secara tersirat tahap politik dan sosial. Setiap mesej media dapat dilihat sebagai ruang kepercayaan mengenai identiti, peranan dan amalan sosial masyarakat tertentu. Dengan nilai yang dimiliki, seseorang akan cuba membangunkan identiti etnik dengan perasaan bermaruah dan juga bangga. Hal ini kerana, identiti etnik yang bermain di alam maya boleh menjadi perangsang untuk kekal aktif dalam dunia etnik mereka. Callaghan dan Lacruz (2017) mendapati bahawa sumber media yang kerap digunakan akan menyebabkan pengekalan identiti etnik secara langsung dan ia menjadi tempat menghabiskan masa untuk mendapatkan info tentang keseluruhan cara hidup generasi etnik mereka. Keadaan ini sangat menonjol kepada negara yang mempunyai penduduk yang heterogeneous kerana mereka menggunakan media untuk menghilangkan rindu kepada etnik mereka (Advani \& Reich, 2015).

Negara yang mempunyai masyarakat heterogeneous tidak dapat membentuk kerana kumpulan-kumpulan kecil dalam negara. Bornman (2018) menjelaskan kebanyakkan negara telah menjadi heterogen kerana penggabungan kumpulan yang lebih kecil. Proses globalisasi, keperluan untuk membentuk hubungan transnasional dan aliran migrasi yang menyatukan telah menjadikannya semakin sukar bagi sesebuah negara untuk menangani 
kepelbagaian. Satu bentuk negara baru - negara multikultural - telah muncul untuk menangani masalah ini. Tiga prinsip negara multikultural dapat dibezakan melalui: pertama, kerajaan adalah milik semua rakyatnya dan bukan hanya kepada kumpulan majoriti dominan; kedua, asimilasi negara bangsa ditolak dan budaya dan warisan sejarah semua kumpulan diiktiraf dan ditampung; dan, ketiga, negara mengambil langkah afirmatif untuk membetulkan apa-apa kerosakan yang dilakukan terhadap bahasa dan budaya mana-mana kumpulan akibat diskriminasi.

Penganalisis media percaya bahawa peranan media telah berubah untuk mencerminkan wajah pelbagai bangsa. Bagi negara heterogeneous, media telah mengalihkan idea satu negara dan satu budaya. Mereka mengingatkan orang ramai bahawa mereka hidup dalam masyarakat yang pelbagai dan membantu mereka memahami bagaimana kepelbagaian mempengaruhi kehidupan dan masyarakat mereka. Tambahan pula, media telah memupuk empati untuk budaya yang lain. Perhatian khususnya perlu diberikan kepada masyarakat yang diputarbelitkan dan stereotip ke atas kumpulan budaya lain. Media perlu melihat bagaimana identiti kumpulan yang dicerminkan (Bornman, 2018).

Mengenai pembentukan identiti, Castells (2010) dalam buku bertajuk "The Power of Identity" telah menumpukan pada amalan, pergerakan sosial dan asal-usul iaitu identiti dalam pelbagai konteks sebagai landasan untuk memahami rangkaian masyarakat. Castells telah mencadangkan tiga jenis pembentukan identiti yang melibatkan rangkaian masyarakat iaitu legitimizing identity, resistance identity dan project identity. Tiga jenis pembentukan identiti bersumberkan dari sejarah, geografi, biologi, institusi produktif dan reproduktif, memori kolektif, imaginasi peribadi, kuasa dan agama. Kesemua sumber ini berkembang merentasi masa melalui media yang digunakan untuk memastikan bahawa matlamat pengekalan identiti dapat dilaksanakan. Castells menjelaskan bahawa pembentukan identiti juga telah membuatkan rangkaian masyarakat ke arah "shaking institutions, transforming cultures". Castells menyifatkan zaman ini dengan pemecahan identiti di mana asas tradisional pengekstrakan telah "twisted, divided, reprocessed, mixed [and] differentially stigmatized or rewarded, according to a new logic of informationalization /globalization of cultures and economies that makes symbolic composites out of blurred identities".

Seiring dengan perkembangan teknologi, Lily El Ferawati et al. (2015) menerangkan media dilihat sebagai sumber utama yang menyediakan imej dan makna budaya bagi penonton untuk mentakrif, membentuk dan mengembangkan semula identiti mereka. Media juga berperanan besar untuk merangsang penyertaan sosial dan politik bagi pengukuhan pembentukan identiti. Lily menjelaskan dalam proses pembentukan identiti, mereka perlu mempertimbangkan konsep verbal untuk memenuhi jangkaan-jangkaan masyarakat bagi menentukan jatidiri dan identiti sosial mereka berkaitan dengan keupayaan seseorang untuk menggunakan agensi kemanusiaan (human agency) mereka dan mempertimbangkan struktur sosial (social structures). la dilakukan dengan simbolik menerusi media yang dinikmati oleh pelayar setiap hari dalam kehidupan mereka melalui pengadaptasian dan memahami nilai-nilai positif dan negatif melalui pengalaman dan pemikiran peribadi yang diperoleh menerusi rakan sebaya dan keluarga dari media.

Artikel ini menganalisis platform media yang digunakan oleh generasi kedua Bawean yang terkait dengan kehidupan mereka. Platform itu akan dianalisis untuk melihat kesan media ke atas pengekalan identiti mereka kerana mereka juga terdedah dengan etnik Melayu yang lain dan sentiasa mengidentifikasikan diri sebagai Melayu mengikut situasi. 


\section{MEDIA DAN PEMBENTUKAN IDENTITI GENERASI KEDUA}

Sanyu (2018) melalui temu bual separa berstruktur yang dijalankan pada tahun 2015 dan 2016 ke atas generasi kedua Ghana di Hamburg, German mendapati rangkaian sosial dalam talian merupakan aspek penting dalam berkongsi pengalaman, memupuk hubungan dan menghubungkan antara mereka yang terlibat. Lingkungan sosial dipertingkatkan dengan bantuan komunikasi yang kerap untuk membina dan mengukuhkan hubungan dalam kalangan mereka yang mempunyai latar belakang budaya yang sama, mewujudkan masyarakat sepunya dalam menghadapi "social exclusion". Hakikat bahawa internet merupakan media yang paling penting dalam kehidupan mereka membuka beberapa isu kerana ia menggabungkan media yang berbeza dalam satu masa iaitu termasuk radio, televisyen, video, akhbar dan mesej segera. Hal ini seperti telah dijelaskan bahawa pendekatan konstruktivis dinamik menjelaskan hubungan antara budaya dan kognitif dengan prinsip akses kepada pengetahuan seperti media (Hong et al., 2000).

Saadia Izzelden (2017) menjelaskan peranan media menjadi alat kepada pembentukan identiti etnik. Ini dijelaskan dengan konsep 'ways of being' dan 'ways of belonging'. Bagi Saadia, Ways of belonging merujuk kepada hubungan kepada sejarah identiti asal iaitu keturunan ibu bapa apabila komuniti etnik melakukan perkongsian di media berkaitan memori, nostalgia dan imaginasi yang lebih penting dari ways of being. Media yang tidak mempunyai batas masa dan tempat untuk diakses membolehkan orang ramai mempertahankan dan membentuk semula wilayah budaya mereka dengan mudah melalui pendekatan 'mencari' berkaitan identiti etnik. Saadia turut menjelaskan bahawa media telah memainkan peranan yang besar dalam meningkatkan kesedaran mereka tentang hal ehwal semasa dan isu-isu yang menjadi perhatian sebenar masyarakat di samping penggalak hal kemanusiaan dan bangsa terutama bagi orang Sudan di Qatar.

Media telah memberi stigma ke atas identiti orang Liberia di Amerika Syarikat. Ludwig (2019) menjelaskan bahawa tekanan kuat dihadapi oleh generasi kedua Liberia. Mereka di Amerika perlu berurusan dengan fahaman besar berkaitan stigma. Sebagai pelarian, mereka menanggung apa yang dikaitkan dengan label "hitam" tersebut. Istilah 'pelarian' dan 'hitam' di Amerika Syarikat sering disamakan dengan masalah beban ekonomi. Di samping itu, imej perang saudara telah merosakkan negara Liberia masih mendominasi media. Oleh kerana perang, banyak ibu bapa Liberia tidak pernah menyelesaikan pendidikan formal mereka dan menyebabkan anak mereka buta huruf serta memaksa mereka bekerja sebagai pembantu rumah. Hal ini salah satu sebab memalukan generasi kedua. Di luar Pulau Staten, menjadi 'Black' adalah satu lagi stigma yang telah dibesar-besarkan dalam media. Bagaimanapun, Ludwig menjelaskan bahawa generasi kedua Liberia lebih menekankan unsur kebudayaan dan warisan Afrika di persekitaran hidup mereka walaupun mengalami tekanan ke atas warna kulit.

Kajian yang dilakukan oleh Alinejad (2017) mendapati generasi kedua Iran di Los Angeles Amerika menggunakan internet untuk mengembangkan identiti secara digital. Alinejad mengkaji bagaimana generasi kedua Iran Amerika ini menggunakan pelbagai platform laman sesawang dalam kehidupan sosial, budaya, dan politik mereka. Alinejad membongkar keperibadian kontemporari menerusi perbincangan pengantaraan digital mengenai kaum, memori dan penglibatan jarak jauh dalam Gerakan Hijau Iran. Amalan laman sesawang media telah menjadi penting kepada pembentukan identiti dengan memperkenalkan konsep "digital style" generasi kedua Iran Amerika serta menjelaskan bahawa aplikasi laman sesawang tertentu mampu membina diaspora budaya baharu. 
Diaspora baharu itu adalah seperti secara aktif mereka menghasilkan naratif sejarah kedudukan mereka sendiri.

Pembentukan identiti generasi kedua yang dinyatakan oleh Schmidt (2011) kepada golongan migran di Denmark mendapati bahawa perkembangan media adalah sebagai "partner" bagi menghasilkan sifat kebersamaan mereka. Denmark sukar memasukkan penduduk dalam kategori Danish kerana terlalu banyak halangan terutama sekali adalah dari segi perkahwinan campur secara berleluasa oleh generasi kedua migran dengan penduduk lokal. Ini menyebabkan halangan khusus kepada dasar integrasi budaya bangsa Denmark telah mewujudkan dilema antara menjamin hak-hak dan kebebasan individu dan mengamankan sempadan komunal negara sendiri. Melalui media, migran banyak mengelak untuk menjadi orang Danish dan lebih banyak bangga menjadi generasi kedua migran.

Di Eropah Sentral, permasalahan tentang generasi kedua migran berlaku khususnya ke atas orang Turki apabila mereka memisahkan segmen yang terpencil dari masyarakat arus perdana seperti dijelaskan oleh Franz dan Götzenbrucker (2012). Generasi kedua Turki semakin terlibat dengan budaya internet dan membangunkan corak baharu interaksi sosial ke dalam kehidupan setiap hari di negara-negara Eropah khususnya di Austria. Sarjana tersebut menjelaskan bahawa media boleh membentuk tingkah laku untuk meningkatkan peluang individu bagi menyelaraskan kejayaan kepada masyarakat majoriti dan perilaku yang mungkin meningkatkan risiko mereka untuk pengasingan sosial. Ini kerana generasi kedua Turki di Austria mengikut kajiannya mendapati bahawa mereka cuba meringankan kedudukan sosial mereka dengan mencari keanggotaan dalam masyarakat maya yang ada sekurang-kurangnya berdasarkan realiti dalam talian. Sekiranya banyak aspek positif diperoleh, maka penyelerasan dalam pembentukan identiti kepada masyarakat Austria akan menebal dan juga boleh menjadi sebaliknya.

Park (2009) dalam kajiannya ke atas orang Korea di Amerika telah membincangkan tentang hubungan antara proses pembinaan identiti generasi Korea Amerika, kedinamikan kumpulan rakan sebaya dan media massa. Generasi kedua warga Korea adalah berbeza daripada ibu bapa mereka dalam erti kata bahawa mereka mempunyai beberapa peringkat pembentukan dalam identiti mereka seperti orang Amerika, orang Korea Amerika dan orang Asia Amerika kerana dipengaruh oleh media. Kajian kualitatif di Boston mendedahkan bahawa perasaan lebih kepada Korea bergantung kepada pengetahuan mereka tentang individu yang ditemui secara online atau offline. Bagi pandangan generasi kedua, pembentukan identiti orang Korea yang datang secara langsung dan lahir di Amerika adalah berbeza. Proses pembentukan identiti pada peringkat ini melalui proses yang rumit dikenali sebagai "akulturasi semula" dan pada tahap ini, kumpulan rakan sebaya Korea Amerika berfungsi sebagai mekanisme sokongan sosial, sedangkan media Korea membantu mereka untuk ikatan dengan rakan-rakan dan keluarga mereka di Negara Korea.

\section{METODOLOGI KAJIAN}

Kajian ini diperoleh berdasarkan pendekatan kualitatif melalui kaedah temu bual mendalam dengan informan dan kajian perpustakaan. Temu bual dianalisis berdasarkan soalan pembentukan budaya identiti yang diperoleh melalui Hong et al. (2001). Falsafah utama dalam kajian ini menggunakan interpretivist paradigm. Penglibatan pengkaji secara langsung dalam mendapatkan makna-makna tindakan sosial tersebut. Kaedah penyelidikan yang digunakan ialah penyelidikan fenomenologi dengan menjelaskan makna konsep atau pengalaman yang dialami oleh subjek kajian. Seramai 13 orang informan ditemu bual dalam kajian ini yang tinggal di perkampungan Bawean di Johor Bahru. Mereka terdiri dari generasi 
kedua dalam lingkungan umur 17-35 tahun. Jenis temu bual adalah temu bual tidak berstruktur. Soalan-soalan dikemukakan kepada informan berkaitan dengan tahap pengekalan identiti etnik. Soalan yang dikemukakan kepada informan mengandungi dua bahagian. Bahagian A iaitu jenis platform media yang digunakan untuk mendapatkan maklumat berkaitan etnik, jumlah jam yang digunakan untuk mendapatkan maklumat berkaitan etnik, maklumat yang diakses, perkara yang dikongsi di media dan jaringan yang diikuti. Bahagian B pula berkaitan kesan penggunaan media ke atas proses pembentukan identiti budaya meliputi soalan ke atas ciri fizikal, personaliti, kemahiran, proses psikologikal serta hak dan tanggugjawab.

\section{HASIL KAJIAN DAN PERBINCANGAN}

\section{Latar Belakang Informan}

Seramai 13 orang informan generasi kedua yang berumur di antara 17-35 tahun telah ditemu bual. Seramai lapan orang lelaki dan lima orang wanita. Sewaktu kajian dijalankan pada tahun 2018, tiga daripadanya masih bersekolah, empat orang melanjutkan pengajian di institut pengajian tinggi dan enam orang telah bekerja. Dua orang bekerja di bahagian perkhidmatan di pusat membeli belah. Dari status diri bagi informan yang telah bekerja, empat orang telah berkahwin dan dua orang masih bujang. Maklumat informan seperti Jadual 1.

Jadual 1: Maklumat Informan

\begin{tabular}{ccclll}
\hline Informan & Umur & Jantina & Pendidikan & Pekerjaan & Status \\
\hline 1 & 34 & Lelaki & Sijil Pelajaran Malaysia & Kilang & Berkahwin \\
2 & 35 & Perempuan & Sijil Pelajaran Malaysia & Kilang & Berkahwin \\
3 & 30 & Lelaki & Sijil Pelajaran Malaysia & Kedai Pembinaan & Berkahwin \\
4 & 20 & Lelaki & Institut Pengajian Tinggi & - & Bujang \\
5 & 19 & Lelaki & Institut Pengajian Tinggi & - & Bujang \\
6 & 17 & Lelaki & Sekolah Menengah & Bujang \\
7 & 25 & Perempuan & Sijil Pelajaran Malaysia & Kerani & Bujang \\
8 & 23 & Perempuan & Sijil Pelajaran Malaysia & Perkhidmatan & Bujang \\
9 & 17 & Lelaki & Sekolah Menengah & - & Berkahwin \\
10 & 28 & Perempuan & Sijil Pelajaran Malaysia & Perkhidmatan \\
11 & 22 & Lelaki & Institut Pengajian Tinggi & - & Bujang \\
12 & 17 & Perempuan & Sekolah Menengah & Bujang \\
13 & 21 & Lelaki & Institut Pengajian Tinggi & - & Bujang \\
\hline
\end{tabular}

\section{1) Penggunaan Media dalam Pengekalan Identiti}

Media khususnya memainkan peranan penting dalam membentuk identiti, persepsi, dan corak tingkah laku seperti yang telah dinyatakan oleh Chorev (2019). Jelasnya lagi, masa kini, media sosial mencerminkan realiti menyuburkan, memperkuat, dan meningkatkan keadaan dengan menyediakan platform untuk munculnya sumber kuasa baharu termasuk subkultur. Media juga menyumbang secara besar-besaran untuk membentuk ciri-ciri langsung keupayaan masyarakat terus mempertahankan dan mengekalkan identiti mereka.

\section{i. Jenis Media yang Digunakan}

Pada masa kini, sumber media adalah pelbagai dalam memberikan dan menyebarkan maklumat kepada audiens atau khalayak. Jenis platform media yang kerap digunakan oleh informan adalah pelbagai. Majoriti informan menjelaskan bahawa Facebook merupakan sumber utama dan kerap digunakan dalam melayari internet. Selain itu, YouTube juga 
memainkan signifikan kepada generasi kedua Bawean untuk menzahirkan perasaan dan tingkahlaku. Majalah serta buku yang mempunyai unsur kehidupan Bawean juga digunakan oleh informan untuk memperkuatkan identiti mereka. Beberapa platform media yang digunakan seperti dinyatakan informan.
"Buku dan majalah berkaitan Bawaean yang disimpan di rumah sebagai panduan identiti" (Informan 3).
"Kalau buka internet, biasa dengar channel radio Indonesia" (Informan 2).
"Dulu ada juga tengok kisah-kisah Bawean dari CD yang ayah simpan.
Sekarang online Facebook lah" (Informan 13).

\section{ii. Jumlah Jam yang Digunakan untuk Mengakses Maklumat}

Berikutan dengan sumber atau platform yang digunakan, secara purata bagi majoriti informan, waktu yang digunakan dalam melayari internet untuk melihat tentang kehidupan Bawean di Malaysia dan Indonesia dianggarkan selama dua hingga tiga jam sehari. Bagaimanapun, ia mengikut keadaan dan apa yang berlaku di kawasan kediaman mereka. Hal ini kerana, jumlah populasi penduduk Bawean di Malaysia dan khususnya di Pulau Bawean tidaklah besar seperti etnik lain. la boleh diketahui seperti apa yang dinyatakan oleh informan berikut.

\footnotetext{
"Biasanya waktu online tengok dalam dua tiga jam juga, tapi tak semua pasal Bawean sebab orang Bawean tak ramai, tak banyak cerita" (Informan 5).

"Kalau online, lebih kurang dua hingga tiga jam sebelum tidur... siang ada juga tapi kejap-kejap. Kerja tak boleh main telefon. Mau kerja tak siap" (Informan 10).

"Waktu main telefon, online macam Facebook, tu dua tiga jam juga time siang, malam pun sama juga. Lebih kurang tu. Banyak main game je" (Informan 11).
}

\section{iii. Perkara yang Diakses}

Informan mengetahui jumlah jam yang digunakan untuk berinteraksi sesama ahli, perkara yang perlu diketengahkan adalah berkaitan dengan apa yang diakses dan peroleh. la menjadi sumber dalam pengekalan identiti. Hal ini menunjukkan bahawa maklumat yang diperoleh akan meningkatkan rasa kebersamaan yang membentuk sosial budaya mereka. Ini seperti apa yang dinyatakan oleh beberapa informan.

\footnotetext{
"Banyak juga CD pasal orang-orang dekat Bawean. Tapi dekat Bawean tak ada TV1, TV3... Video tu rakam sendiri masuk CD. Banyak pasal budaya macam persembahan orang-orang Bawean, pasal bahasa dan hubungan orang-orang di Bawean tu" (Informan 12).

"Kalau di kampong ini, kampong Bawean di bandar (Johor Bahru), segala aktiviti dirakam dan disimpan oleh persatuan dan sendiri-sendiri, Persatuan Bawean di Johor ni juga aktif. tetapi tak selalu acara dilakukan. Kena libatkan diri macam saya di majlis-majlis supaya boleh tengok dan rasa sendiri. Buat koleksi" (Informan 1).
} 
"Maklumat ini adalah untuk dijadikan panduan tentang asal usul Bawean. Sebab tak ramai yang menulis, hanya cerita. Buku dengan majalah ini dapat masa balik Bawean dan Indonesia" (Informan 4).

\title{
iv. Perkara yang Dikongsi di Media
}

Informan memiliki etnisiti tersendiri dapat memahami budaya dan identiti. Mereka lebih menitikberatkan soal kelangsungan identiti. Hal ini kerana identiti orang Bawean menjadi asas kepada mereka untuk menempuh kehidupan. la ditambah apabila pesanan secara lisan diturunkan oleh generasi pertama. Oleh demikian, dengan adanya platform media, mereka dapat menyerlahkan lagi etnisiti mereka dengan perkongsian identiti di platform media. Perkara ini boleh diketahui dengan jawapan beberapa informan berikut

\begin{abstract}
"Dah ada Facebook, senang. Boleh tengok-tengok sejarah lama. Ada juga share pasal budaya Bawean kat Facebook macam majlis raya" (Informan 6).

"Zaman sekarang ni, semua guna Facebook untuk tunjuk budaya masingmasing. Ada yang dekat YouTube. Kadang kita share dari YouTube pasal makanan, tempat pelancongan. Dulu ada pergi bawean, ambik gambar masuk Facebook" (Informan 8).

"Biasa kongsi perayaan orang Bawean supaya orang Bawean seluruh negara tahu ada acara. Kalau di KL, ada tiap-tiap tahun. Mereka kongsi dekat Facebook, kita share dekat Facebook. Majlis orang Bawean beza dengan majlis orang Melayu yang lain, unik skit" (Informan 9).
\end{abstract}

\section{v. Jaringan yang Diikuti}

Pengekalan identiti dapat diteruskan apabila terdapat kebolehan melaksanakan identiti oleh generasi ke generasi seterusnya. la terkait dengan platform media yang memaparkan ikutan kelompok tertentu untuk mengekalkan dan seterusnya mengekpresikan identiti secara realiti mahupun di dalam media komunikasi. Oleh itu, rangkaian menjadi sumber rujukan untuk memastikan segala hajat identiti boleh dilaksanakan. Perkara ini boleh difahami seperti kenyataan oleh beberapa informan.

“Orang Bawean ni, penduduk tak ramai, kalau di Facebook boleh tengok orang-orang Bawean kena follow pages orang Bawean atau group-group Bawean" (Informan 6).

"Dekat Facebook, ada group orang-orang Bawean, dekat situ boleh borakborak dalam Bahasa Bawean, belajar Bahasa Bawean juga" (Informan 8).

"Persatuan Bawean ada buat page dan group pasal Bawean satu dunia. Dalam tu orang semua kongsi. Semua dekat pages orang Bawean akan update macam-macam. Jadi boleh tahu dekat situ. Ada pasal legenda, cerita lucu, pasal kematian orang besar. Biasanya aktiviti orang Bawean seluruh dunia" (Informan 12).

Kenyataan informan berkaitan penggunaan media dalam pengekalan identiti, jelaslah menunjukkan media tidak boleh menjadi terpisah-pisah dalam kehidupan mereka. Segala proses kehidupan yang dijalani banyak disosialisasikan dari media. Penggunaan 
media dimanfaat sebaik mungkin untuk mempelajari, berkongsi dan mengamalkan budaya mereka supaya etnik mereka terus kekal walaupun diintegrasikan dalam budaya Melayu di Malaysia. Hal ini selari dengan pandangan McEwan (2019) ke atas penduduk asal New Zealand bahawa platform media telah memberikan inisiatif kepada individu sebagai strategi untuk memperbaiki kemerosotan dalam budaya serta dapat mempromosi identiti. Menurut McEwan lagi, media adalah proses penumpuan bagi menzahirkan kandungan identiti. Platform media telah menjadi perantara untuk pemeliharaan dan suara seperti mana yang terjadi ke atas identiti Māori.

Kemajuan teknologi membuka ruang untuk masyarakat memperkenalkan identiti masing-masing kerana kemudahan untuk sebaran identiti telah menjadi mudah. Sebaran identiti tidak lagi terikat kepada kaedah tradisional. la boleh diakses berulang-ulang kerana segala maklumat disimpan di dalam jaringan komunikasi tanpa henti. Seperti yang diperkatakan oleh Alia (2010), masyarakat telah menggunakan teknologi baharu di seluruh dunia untuk menguatkan suara mereka serta menyiarkan maklumat kepada khalayak secara global. Ini adalah potret gerakan antarabangsa yang kuat untuk membantu mengekalkan bahasa dan budaya semasa berkomunikasi di sempadan budaya, politik dan geografi yang berbeza. Penggunaan media yang lama dan luas dapat 'mix dan match' aspek identiti untuk membina jenis peribadi etnisiti. Hal ini berlaku seperti mana ke atas generasi kedua apabila mereka memahami keperluan untuk mengekalkan identiti melalui media.

\section{2) Kesan Penggunaan Media ke atas Pembentukan Identiti}

Penggunaan media ke atas pembentukan identiti pada abad ke 21 sememangnya memainkan peranan penting. Beberapa perkara asas kepada identiti diserap dan diterjemahkan dalam kehidupan seharian apabila rasa etnosentrik menebal. Bagi golongan belia seperti mana yang dijelaskan oleh Wright (2020) bahawa media digital adalah modal popular di mana mereka mencari, mendapatkan secara sedar atau tidak sedar jawapan yang bermakna kepada soalan-soalan berkaitan mereka. Ruang multi modal adalah tapak untuk pembinaan identiti dan peluang untuk mencipta naratif diri. Soalan yang berasaskan pembentukan identiti budaya daripada Hong et al. (2001) telah menjadi panduan dalam temu bual. Generasi kedua orang Bawean mengekalkan identiti mereka dengan melihat diri mereka secara langsung dan melihat diri mereka melalui pandangan masyarakat. Pandangan masyarakat sangat penting untuk memastikan ciri budaya etnik mereka tidaklah menjadi konflik kepada masyarakat lain. Hal ini kerana mereka perlu memastikan bahawa nama baik etnik dapat dipertahankan. Terdapat lima kesan yang dnyatakan oleh Hong et al. (2001) mengenai pembentukan identiti iaitu ciri fizikal, personaliti, kemampuan, proses psikologikal, tanggungjawab dan hak.

\section{a) Ciri Fizikal}

Berdasarkan ciri fizikal yang berkaitan dengan karakteristik, masyarakat Bawean khususnya generasi kedua sudah dapat menerima penilaian atau "judgments" orang luar terhadap identiti mereka. Di dalam media, andaian terhadap karakteristik mereka adalah banyak berkaitan dengan susuk tubuh mereka yang kurus dan tegap. Ciri fizikal yang lain tidak terlalu ketara dengan identiti sosial etnik yang lain. Hal ini boleh difahami melalui kenyataan informan.

"Banyak orang tak percaya orang Bawean yang kurus-kurus boleh angkat benda besar, benda berat. Badan tak besar tapi kuat" (Informan 3). 


\begin{abstract}
“Orang luar banyak anggap orang Bawean ni kurus-kurus sebab kuat kerja angkat benda berat-berat. Pasal perempuan, badan perempuan tak banyak beza dengan orang Melayu lain. Kalau di Bawean, mereka tak gemuk-gemuk, di sini je gemuk, sini pun dah boleh terima. Pandangan perempuan kat sana (Bawean) tak sama" (Informan 7).

"Pernah baca dekat Facebook, orang Bawean tu macam badang. Badan tak kecik tak besar, tapi kalau suruh angkat benda berat, takda masalah. Sebab banyak yang kerja buat rumah." (Informan 5).
\end{abstract}

\title{
b) Personaliti
}

Dari segi personaliti, pandangan umum dari persekitaran masyarakat yang dialami oleh generasi kedua orang Bawean sama ada dalam bentuk media atau tidak, telah memberikan satu pegangan dalam kehidupan mereka. Orang Bawean mementingkan adat yang sentiasa menjaga keharmonian sesama mereka. Hal ini kerana dari segi adat mereka inilah yang membentuk personaliti etnik mereka. la dikembangkan melalui media-media seperti tulisan, potret dan dokumentari. Perkara personaliti yang menjadi pegangan kuat mereka adalah orang Bawean dikatakan saling bantu membantu dan tidak suka terlibat dengan pergaduhan. la merupakan nilai personaliti yang wajib seperti kenyataan informan.

"Dekat dalam internet, orang kenal Bawean sebagai orang yang suka tolong menolong. Banyak sebab kerja, nak cari duit untuk keluarga dan kampung. Penduduk tak ramai, jadi kena kerja kuat untuk bantu orang-orang Bawean supaya tak gaduh" (Informan 2).

"Dari dulu memang orang Bawean ni suka tolong menolong, sebab semua duduk satu tempat. Kalau majlis, semua turun bantu, ada bahagi-bahagi kerja. Ada ketua, jadi memang tolong bantu memang dah jadi biasa" (Informan 1).

"Bukan untuk orang lain, untuk bangsa sendiri. Kalau tak tolong, bangsa susah. Jadi masam muka. Memang orang Bawean tak suka gaduh-gaduh, gotong royong lah, dari budak kecik sampai orang tua, kena ajar tolong menolong" (Informan 6).

\section{c) Kemahiran}

Setiap bangsa mempunyai ciri khas yang tersendiri yang diangkat sebagai sebahagian identiti. la akan meningkatkan perasaan bangga kepada bangsa sehingga menjadi sebutan. Kemampuan sesuatu bangsa sangat terkait kemahiran menyesuaikan alam semulajadi dengan kehidupan mereka. Sebagai contoh, orang asli yang menetap di kawasan hutan dan pergunungan dapat menggunakan tumbuhan sebagai ubat-ubatan. Begitu juga dalam pembentukan identiti Bawean. Orang Bawean menjadi sebutan dengan kemahiran yang tersendiri seperti kenyataan informan.

"Orang dulu cerita sampai sekarang jadi identiti orang Bawean itu pasal pandai buat rumah. Tu yang paling utama. Macam rumah ni, sendiri buat cuma saudara mara tolong. Tak ada upah orang luar. Banyak rumah buat sendiri sampai ada orang Pahang datang nak tengok rumah-rumah orang Bawean dekat sini. Dah masuk Facebook. Semua jadi tahu" (Informan 9). 
"Jika di Bawean, orang Bawean sangat mahir membina rumah dengan tanah dan tinggal di lereng-lereng bukit. Kalau dekat sini, laju buat rumah orang, sebab dulu mereka memang kerja bina rumah" (Informan 4).

"Kemampuan orang Bawean tu banyak, kalau dekat laut, lain, dekat bukit lain. Mereka banyak kemahiran. Dekat Pulau Bawean kalau tak mahir, susah nak hidup, cuaca tak macam Malaysia" (Informan 10).

\section{d) Proses Psikologikal}

Menerima andaian orang luar terhadap identiti bukanlah sesuatu yang mudah dihadapi jika andaian itu lebih memberat ke arah andaian negatif. Proses psikologikal dapat membantu menapis andaian negatif dengan amalan kepercayaan dan nilai-nilai pegangan adat yang diamalkan. Kepercayaan dan nilai yang merupakan sebahagian pembentukan identiti dijadikan asas kepada kekuatan etnik. la bagi mengelakkan andaian negatif tertanam ke atas identiti etnik mereka. Bagi orang Bawean, kepercayaan mereka dapat meningkatkan kebersamaan dengan masyarakat sekitar. la hasil berlandaskan nilai-nilai ajaran Agama Islam seperti kenyataan informan

"Agama orang Bawean 100\% adalah Islam. Jadi bila agama sama dengan orang Islam lain tu senang. Tak ada pandang serong. Tak macam orang Jawa, bukan semua Muslim. Sebab banyak lagi suku-suku. Tapi dekat Malaysia, orang Jawa sini semua Islam. Jadi senang. Dalam Facebook, orang tengok sambut perayaan sama macam Melayu" (Informan 5).

"Orang Bawean pun orang Islam sama dengan orang Melayu dekat sini (Malaysia). Tak susah nak campur. Cara sembahyang semua sama. Boleh hidup dengan orang Melayu. Tak ada isu walaupun kampung ni ada surau sendiri" (Informan 8).

"Paling penting tak ada beza ajaran Islam orang Bawean dengan orang Melayu. Boleh sama amalkan Islam. Saudara seagama. Orang luar tengok pun tak ada beza sebab sama agama" (Informan 7).

\section{e) Hak dan Tanggungjawab}

Kehidupan rakyat adalah terletak di bawah peruntukan perundangan sesebuah negara untuk dilindungi mahupun memberi sumbangan kepada negara. Rakyat juga semestinya menjalankan kewajipan sebagai rakyat untuk memastikan keamanan dan keselamatan negara berkekalan. Bagi generasi kedua Bawean, hak dan tanggungjawab mereka sebagai orang Bawean dipupuk untuk dijadikan pegangan berterusan supaya kebudayaan mereka tidak terjejas. Bagi hal berkenaan, terdapat ketua yang akan memastikan orang Bawean tidak melakukan kesalahan sehingga menyebabkan isu terkait dengan hak dan tanggungjawab. la seperti dinyatakan oleh informan berikut.

"Ketua memang jadi ikutan orang Bawean supaya patuh dengan kerajaan supaya apa yang kerajaan beri, ketua dapat maklumkan kepada penduduk. Kalau politik, memang ikut ketua, ketua nak pastikan orang Bawean kemudian hari tak ada masalah" (Informan 9).

"Dah jadi kewajipan orang Bawean ikut peraturan atau undang-undang dekat Malaysia. Semua tu tunjuk ajar ketua, sebab kalau tak ikut ketua, jadi masalah dekat orang Bawean. Dekat kampung ni masih ramai lagi masih IC 
(kad pengenalan) merah, tak boleh suka-suka buat masalah. Ada IC biru pun kena ikut peraturan" (Informan 10).

"Orang Bawean ada ketua kampung, mana-mana kaum ada ketua tapi ketua orang Bawean dekat sini hanya sebagai ketua untuk orang Bawean. Ketua ini banyak sahabat dengan ketua kampung dekat pejabat penghulu" (Informan 3).

Umumnya, kandungan dari media telah memastikan kecenderungan pengekalan identiti. Ini boleh dilihat dengan jawapan informan mengenai pembentukan identiti seperti ciri fizikal, personaliti, kemahiran, proses psikologikal yang diperoleh kepada akses penggunaan media. Media tidak hanya memberikan platform untuk mengentengahkan identiti etnik mereka tetapi memberikan kesan terhadap kehidupan seharian. Kesan ini adalah sebahagian dari strategi pembangunan identiti. Kesan media ini secara tidak langsung membolehkan identiti generasi kedua kekal dalam persaingan kebudayaan masyarakat dalam sesebuah negara terutamanya multi etnik. Hal ini telah selari disepakati oleh Mengel dan Siibak (2019) apabila menjelaskan bahawa khususnya generasi muda telah diperhatikan membina identiti dari kesan teknologi dan peranti yang mereka gunakan.

Generasi kedua Bawean menjalani kehidupan mereka berdasarkan sosialisasi maklumat yang diterima dari media. Pengikut di dalam talian seperti media sosial boleh mempengaruhi dan dipengaruhi untuk sentimen pembentukan identiti. Maka, 'sense of ethnicity' sentiasa aktif. Warisan budaya yang diaktifkan sepanjang masa melalui saluran media telah meningkatkan kecekapan generasi kedua Bawean berinteraksi. Oleh itu, nilai identiti yang dipegang bersama sentiasa disalurkan ke media untuk menunjukkan emosi solidariti dan diiktiraf oleh masyarakat pelbagai etnik. Proses pembentukan identiti generasi kedua Bawean sangat terkesan kerana media telah mengambil alih peranan komunikasi secara lisan yang digunakan sebelum ini. la bertepatan dengan apa yang dinyatakan oleh Jamilah et al. (2019) bahawa individu yang mempunyai pengetahuan, kemahiran dan emosi dalam menggunakan media secara berkesan telah menghasilkan atau mengkonstruk identiti kendiri dan dapat memenuhi kemahuan dan kehendak mereka.

Kebergantungan generasi kedua Bawean terhadap media sangat luas sehingga proses pembentukan identiti melibatkan persekitaran sosial mereka lebih-lebih lagi adalah golongan awal belia kerana mereka mempunyai masa yang lama untuk menafsirkan identiti dalam kehidupan mereka. Hal ini selari dengan pandangan dari kajian Normah Mustaffa et al. (2013) yang mengupas kebergantungan remaja kepada internet adalah untuk memahami persekitaran sosial, untuk berinteraksi dan juga memenuhi keperluan sosial berbanding keperluan sendiri dengan menggunakan laman jaringan sosial yang paling digemari untuk aktiviti interaksi. Mayhew dan Weigle (2018) juga sependapat bahawa media menghubungkan dan membentuk identiti remaja. Pendidikan media perlu diberi tumpuan yang lebih kerana ia akan menjadi ikutan sepanjang hidup. Secara tidak langsung ia menjadi asas kepada sosialisasi kepada mereka (Wright, 2020). Secara keseluruhannya, pembentukan identiti budaya banyak dipengaruhi oleh media kerana proses identiti seperti pembentukan, pengekalan dan perubahan. la diaktifkan berdasarkan keadaan private, publik, dan kolektif dalam memastikan kerelevanan etnik mereka sentiasa berlangsung. Hal ini selari dengan kajian Hong et al. (2001) yang menjelaskan bahawa proses identiti sentiasa mengambil bahagian dalam semua situasi kehidupan apabila kedinamikan etnik boleh menyumbang kepada pengekalan identiti. 


\section{KESIMPULAN}

Pembentukan identiti generasi kedua orang Bawean adalah bersumberkan dari media kerana golongan ini merupakan generasi yang banyak memanfaatkan teknologi. Pemilihan kepada akses media seperti jaringan internet telah memupuk satu budaya yang universal kerana sama-sama berkongsi keperluan sosial. Pembentukan identiti generasi kedua lebih menonjol berbanding generasi sebelumnya iaitu generasi ibu bapa mereka. Sosialisasi ke atas identiti melalui media cetak dan media elektronik menunjukkan bahawa maklumat yang diperoleh sangat penting supaya ia dapat dikekalkan selama-mana identiti itu perlu dipertonjolkan. Keunikan identiti etnik akan menarik lebih ramai audiens apabila dapat dilihat. Hal ini dilakukan oleh generasi kedua Orang Bawean dalam memartabatkan identiti.

Apa yang boleh dijelaskan, generasi kedua Orang Bawean menggunakan peluang kemudahan teknologi dengan melakukan dan mengamalkan identiti bagi mengekpreskan identiti etnik mereka. Pembentukan identiti melalui tindakbalas persekitaran sosial mereka berdasarkan media dipenuhi dan dikawal melalui pelbagai perkara. Kewajipan mereka adalah dengan mempertahankan serta mengekalkan identiti melalui pandangan masyarakat luar ke atas unsur pembentukan identiti seperti ciri fizikal sehingga hak dan tanggungjawab. Hal ini adalah penting kerana ia merupakan cerminan identiti etnik mereka supaya kekal diterima.

Oleh yang demikian, cadangan supaya kandungan pembentukan identiti etnik perlulah diteroka dan dipersembahkan di media bagi membuka peluang kepada kajian yang lebih luas dan mendalam. Kepelbagaian identiti etnik yang diperoleh dari media akan memberikan jalan keluar dalam mengurangkan salah faham dan dapat meningkatkan komunikasi berkesan. Hal ini kerana identiti etnik merupakan identiti pertama yang dilihat dalam diri seseorang bagi memulakan komunikasi.

\section{BIODATA}

Muhammad Ridhwan Sarifin merupakan pensyarah kanan di Jabatan Pengajian Kemasyarakatan Dan Kewarganegaraan, Fakulti Sains Kemanusiaan, Universiti Pendidikan Sultan Idris. Bidang kepakaran beliau adalah kajian negara bangsa, identiti etnik dan migrasi. Email: ridhwan.sarifin@fsk.upsi.edu.my

Mohd Fauzi Sukimi merupakan pensyarah kanan di Pusat Pengajian Sosial, FSSK, Universiti Kebangsaan Malaysia. Bidang kepakaran adalah sosiologi pembangunan. Email: fauzi@ukm.edu.my

Mohd Nor Shahizan Ali merupakan Professor Madya di Pusat Kajian Media dan Komunikasi, FSSK, Universiti Kebangsaan Malaysia. Bidang kepakaran beliau ialah penyiaran (dokumentari), komunikasi visual, dan literasi media. Email: shahizan@ukm.edu.my 


\section{RUJUKAN}

Arun, A., \& Bryony, R. (2015). Melting pot or salad bowl: The formation of heterogeneous communities. IFS Working Paper W15/30. The Institute for Fiscal Studies. https://www.ifs.org.uk/uploads/publications/wps/WP201530.pdf

Alinejad, D. (2017). The internet and formations of Iranian American-ness. Next generation Diaspora, 1-201. https://doi.org/10.1007/978-3-319-47626-1

Banks, M., \& Jay, R. (2011). Made to be seen: Historical perspectives on visual anthropology. University of Chicago Press.

Bornman, E. (2018). The state, diversity and the media: Some notes on the situation in South Africa. Tydskrif vir Geesteswetenskappe, 58(4), 683-700.

Castells, M. (2010). The power of identity - The information age: economy, society, and culture (2nd ed.). John Wiley \& Sons Ltd.

Chorev, H. (2019). Palestinian social media and lone-wolf attacks: Subculture, legitimization, and epidemic. Terrorism and Political Violence, 31(6), 1284-1306.

Clément, R., Baker, S. C., Josephson, G., \& Noels, K. A. (2005). Media effects on ethnic identity among linguistic majorities and minorities: A longitudinal study of a bilingual setting. Human Communication Research, 31(3), 399-422.

Creswell, J. W. (1998). Qualitative inquiry and research design: Choosing among five traditions. Sage Publication.

Eddy, M. D. (2013). The shape of knowledge: Children and the visual culture of literacy and numeracy. Science in Context, 26(2), 215-245.

Franz, B., \& Götzenbrucker, G. (2012). The second generation and the use of the internet: Communication and friendship structures of young Turks in Vienna, Austria. International Journal of Humanities and Social Science, 2(5), 38-49.

Gündüz, U. (2017). The effect of social media on identity construction. Mediterranean Journal of Social Sciences, 8(5), 85-92.

Hong, Y. Y., Ip, G., Chiu, C. Y., Morris, M. W., \& Menon, T. (2001). Cultural identity and dynamic construction of the self: Collective duties and individual rights in Chinese and American cultures. SocialCognition, 19, 251-268.

Hong, Y., Morris, M. W., Chiu, C., \& Benet-Martinez, V. (2000). Multicultural minds: A dynamic constructivist approach to culture and cognition. American Psychologist, 55, 709-720.

Jamilah Maliki, Normah Mustaffa, \& Mohd Nor Shahizan Ali. (2019). Konstruksi identiti dalam talian daripada perspektif pengguna Facebook. Jurnal Komunikasi: Malaysian Journal of Communication, 35(4), 119-134.

Lily El Ferawati Rofil, Md Azalanshah Md Syed \& Azizah Hamzah. (2015). "Jadi Melayu": Televisyen dan pembentukan identiti wanita kuturunan Jawa di Malaysia. Jurnal Komunikasi: Malaysian Journal of Communication, 31(1), 41-58.

Ludwig, B. (2019). It is tough to be a Liberian refugee in Staten Island, NY: The importance of context for second generation African immigrant youth. African and Black Diaspora, $12(2), 189-210$.

Malik, S. I. (2017). Identity, citizenship and 'home' through the transnational perspective(s) of second generation Sudanese migrants in Qatar. Diaspora Studies, 10(2), 175-192.

Manago, A. M. (2015). Media and the development of identity. In R. Scott \& S. Kosslyn (Eds,), Emerging trends in the social and behavioral sciences (pp. 1-14). John Wiley \& Sons, Inc. 
Martinez-Callaghan, J., \& Gil-Lacruz, M. (2017). Developing identity, sense of belonging and social networks among Japanese immigrants in Scotland and Spain. Asian and Pacific Migration Journal, 26(2), 241-261.

Maslida Yusof. (2018). Trend ganti nama diri bahasa Melayu dalam konteks media sosial. Jurnal Komunikasi: Malaysian Journal of Communication, 34(2), 36-50.

Mayhew, A., \& Weigle, P. (2018). Media engagement and identity formation among minority youth. Child and Adolescent Psychiatric Clinics of North America, 27(2), 269285. https://doi.org/10.1016/i.chc.2017.11.012

McEwan, R. (2019). Iwi radio in the era of media convergence: The opportunities and challenges of becoming 'more than radio'. Terrorism Dilemmas and Democracy, 25(1\&2), 139-157.

Murumaa-Mengel, M., \& Siibak, A. (2019). Compelled to be an outsider: How students on a social media detox self-construct their generation. Comunicazioni Sociali, 2, 263-275.

Merriam, S. B. (2001). Qualitative research and case study applications in education. Jossey Brass Publication.

Mistry, J., Berardi, A., Tschirhart, C., Jafferally, D., \& de Ville, G. (2015). Indigenous identity and environmental governance in Guyana, South America. Cultural Geographies, 22(4), 689-712.

Mobasher, M. (2006). Cultural trauma and ethnic identity formation among Iranian immigrants in the United States. American Behavioral Scientist, 50(1), 100-117.

Normah Mustaffa, Wan Amizah Wan Mahmud, Fauziah Ahmad, Maizatul Haizan Mahbob, \& Mohd. Helmi Abd. Rahim. (2013). Kebergantungan internet dan aktiviti online remaja di Lembah Kelang. Jurnal Komunikasi: Malaysian Journal of Communication, 29(1), 199-212.

Nunes, F. (2019). Critical and intersectional perspectives on immigrant youth cultural identity. International Journal of Mental Health and Addiction, 14(74), 1-10.

Park, S. (2009). Negotiating identities and re-acculturation of second-generation Korean Americans: The role of ethnic media and peer group dynamics. Korea Journal, 49(1), 61-97.

Sanyu, A. M. (2018). 'New media, diasporic identity and social exclusion: A study of everyday practices of identity negotiation among second-generation Ghanaian women in Hamburg'. Crossings: Journal of Migration \& Culture, 9(1), 29-43.

Saucier, P. K. (2009). CVSpace: Musings on cape verdean youth identity, technology, and myspace. American Communication Journal, 11(1), 1-11.

Schmidt, G. (2011). Law and identity: Transnational arranged marriages and the boundaries of danishness. Journal of Ethnic and Migration Studies, 37(2), 257-275.

Turner, B. S. (2006). The Cambridge dictionary of sociology. Cambridge University Press.

Valerie, A. (2010). The new media nation: Indigenous peoples and global communication. Berghahn Books.

Wright, E. (2020). Nurturing identity formation in adolescence through narrative learning: A dialogue between the pedagogies of media literacy and religious education. British Journal of Religious Education, 42(1), 14-24.

Yücel, H. (2019). Cultural identity in Turkish advertisements. Jounal of Social Semiotics, 1-19. 